\title{
NUMERICAL INVESTIGATION OF DAMPING EFFECTS ON COUPLED HEAVE AND PITCH MOTION OF AN INNOVATIVE DEEP DRAFT MULTI-SPAR
}

\author{
Bin-Bin Li \\ School of Civil Engineering, Harbin Institute of Technology, Harbin, P.R. China., libinbin01@tsinghua.org.cn \\ Jin-Ping Ou \\ School of Civil \& Hydraulic Engineering, Dalian University of Technology, Dalian, P.R. China. \\ Bin Teng \\ School of Civil \& Hydraulic Engineering, Dalian University of Technology, Dalian, P.R. China.
}

Follow this and additional works at: https://jmstt.ntou.edu.tw/journal

Part of the Civil and Environmental Engineering Commons

\author{
Recommended Citation \\ Li, Bin-Bin; Ou, Jin-Ping; and Teng, Bin (2011) "NUMERICAL INVESTIGATION OF DAMPING EFFECTS ON COUPLED \\ HEAVE AND PITCH MOTION OF AN INNOVATIVE DEEP DRAFT MULTI-SPAR," Journal of Marine Science and \\ Technology. Vol. 19: Iss. 2, Article 15. \\ DOI: $10.51400 / 2709-6998.2158$ \\ Available at: https://jmstt.ntou.edu.tw/journal/vol19/iss2/15 \\ This Research Article is brought to you for free and open access by Journal of Marine Science and Technology. It has been \\ accepted for inclusion in Journal of Marine Science and Technology by an authorized editor of Journal of Marine Science and \\ Technology.
}




\section{NUMERICAL INVESTIGATION OF DAMPING EFFECTS ON COUPLED HEAVE AND}

PITCH MOTION OF AN INNOVATIVE DEEP DRAFT MULTI-SPAR

\section{Acknowledgements}

This research work was financially supported by the National High Technology Research and Development Program of China (863 Program) under Grant No. 2006AA09A103 and National ScienceTechnology Major Project (No. 2008ZX 05056-03). 


\title{
NUMERICAL INVESTIGATION OF DAMPING EFFECTS ON COUPLED HEAVE AND PITCH MOTION OF AN INNOVATIVE DEEP DRAFT MULTI-SPAR
}

\author{
Bin-Bin $\mathrm{Li}^{*}$, Jin-Ping $\mathrm{Ou}^{* *}$, and Bin Teng**
}

Key words: Mathieu instability, damping, coupled model, Spar, mooring line.

\begin{abstract}
Deep draft multi-spar (DDMS), a novel deepwater platform, possesses the similar hydrodynamic and motion performances with the Spar platform. Therefore the DDMS may have instability of Mathieu's type because the heave natural period is close to the half pitch natural period. The objective of this paper is to numerically study the damping effects on the Mathieu instability and the mechanism of this singular phenomena. In this simulation, the damping is determined through the free-decay tests based on a rigorous coupled hull and mooring model. The nonlinear motion equations of coupled heave and pitch considering the time-varying restoring forces are established and solved with six damping cases by using the 4th order Runge-Kutta method. Five regular wave cases of different wave heights and periods including heave natural period and half pitch natural period are conducted. The results indicate that the heave damping significantly influences the occurrence of pitch instability, meanwhile the damping contribution of heave plates and mooring lines also play an important role. Three types of pitch instability are concluded. Finally, four random wave conditions including two swell wave cases and two 100-y return period conditions for South China sea and Gulf of Mexico are applied. The calculated results show that the DDMS platform does not suffer from the Mathieu instability under these real ocean environments.
\end{abstract}

\section{INTRODUCTION}

Since the first Spar platform employed in Gulf of Mexico

Paper submitted 03/01/10; revised 06/05/10; accepted 06/20/10. Author for correspondence: Bin-bin Li (e-mail: libinbin01@tsinghua.org.cn).

*School of Civil Engineering, Harbin Institute of Technology, Harbin, P.R. China.

**School of Civil \& Hydraulic Engineering, Dalian University of Technology, Dalian, P.R. China.
(GOM) in 1996, these facilities of cylinder-type have been widely used for deepwater drilling, oil and natural gas production and storage. Up to now, there are 18 platforms in service around the world involving Classic Spar, truss Spar and cell Spar, and the newest project is the Perdido in GOM which has broken the water depth record with $2400 \mathrm{~m}$. In common and even extreme weather conditions, the heave and pitch responses of Spar platform are considered small, so we usually suppose some parameters constant e.g. the area of steel water and displaced volume. This treatment ordinarily gives satisfied results, but seriously underestimates the pitch response when large heave motion is induced by the wave whose exciting period is near to the heave natural period e.g. swell wave condition. This issue is described as a Mathieu instability, which is probably triggered when pitch natural period is twice the heave natural period. Based on the statistical data, the Spar platforms have 50 65 s pitch natural period and 25 30 s heave natural period, hereby the period ratio is nearly 2 which has fallen into the range of principle unstable zone of Mathieu instability. Earliest, Halsum and Faltinsen [1] studied the Mathieu instability in pitch response with large heave resonance through simplified calculation and model tests, and illustrated a stability diagram for Mathieu's equation without pitch damping. Rho et al. [10] recorded this phenomena through tests of a Classic Spar model with a scale of 1/400, and thought that the damping in heave and pitch resisted the occurrence of Mathieu instability. Rho et al. [9] extended their experiment study to a Truss Spar in 2004, and concluded that the stability of Truss Spar is better than Classic Spar due to heave damping contributed by heave plates and truss members. Koo et al. [3] solved the Classic Spar's responses by using simple coupled heave and pitch equation under regular and irregular waves, and specially analyzed the damping and additional stiffness effects on Mathieu instability. Meanwhile, they concluded that the damping significantly controls the occurrence of Mathieu instability, and consequently which needed to be accurately estimated. Hong et al. [2] executed some experiments by using a series of Spar models especially involving models of which natural period of pitch is twice compared to the heave resonant period as well as the model 
attached heave plates or strakes. They observed that the damping of heave plates and strakes have positive effects to resist the pitch instability. Liu et al. [7] proposed a relative rigorous coupled equation of heave and pitch based on the derivation of theoretical change of stability and displacement volume. They appropriately simplified the coupled equation and numerically calculated the occurrence of Mathieu unstable motion by using a hypothetic damping ratio for a Classic Spar.

One important advantage of Spar platform is the outstanding motion performance to withstand the 1st wave action because its natural periods are out of wave control range as well as its special geometrical configuration. Due to the benefits brought by the favorable motion behavior, the dry tree drilling system and the steel vertical risers can be employed. However, some issues including great fabrication difficulty, relative narrow space of topside and strong VIV effect due to Spar's single column are still big challenges, therefore new types of deepwater platforms are expected to appear in order to solve the problems previously. After summarizing the general requirements and comparing the features between Spar platform and the other types e.g. TLP and Semi, $\mathrm{Li}$ and $\mathrm{Ou}$ [4] proposed an innovative concept platform, Deep Draft Multi-spar (DDMS) in 2008. Similar with the hard tank configuration of the Cell Spar which is the 3rd generation of the Spar's family, the DDMS's hull consists of five deep draft columns; in addition, the mooring lines and top tension risers are used to keep platform position, oil production and well drilling. DDMS is a new conceptual platform for deepwater, whose motion behavior resembles the Spar [5] because of the hard tank of deep draft, and the pitch/heave period ratio is close to 2. Therefore, DDMS platform still has the possibility to subjected to the Mathieu instability which should be significantly studied consequently. It is well known that the platform damping generally comes from some resources including hull radiation damping, hull viscous damping, hydrodynamic damping of mooring line and contact damping between mooring line and seabed etc. The damping and nonlinear tension of mooring line are very important with the increase of water depth, however the conventional experiential estimation is not accurate unless the rigorous interaction between the mooring line and platform in time domain is considered $[8,11]$. Therefore In this paper, a coupled hull and mooring strategy is employed [6], which means the fairlead position of platform captured from the previous step is regarded as the upper boundary condition for dynamic analysis of mooring line whose results also affect the platform motion at next step. Because of the application of semi-tight mooring system, the contact damping from mooring line and seabed is ignored. In addition, hull viscous damping which is proportional to the square of platform velocity significantly influences the low frequency (L-F) motion of platform because the radiation damping is nearly zero in this frequency region. Meanwhile, the nonlinear damping from heave plates needs to be estimated correctly and accounted in the hydrodynamic analysis. In this paper, the total damping effect is represented by using linear damping
Table 1. Characteristic parameters.

\begin{tabular}{|l|c|}
\hline \multicolumn{1}{|c|}{ Item } & Value \\
\hline Diameter of single spar $(\mathrm{m})$ & 12.50 \\
\hline Distance between spars $(\mathrm{m})$ & 35.50 \\
\hline Outer diameter of moonpool $(\mathrm{m})$ & 18.00 \\
\hline Height of spar $(\mathrm{m})$ & 99.60 \\
\hline Total displacement $(\mathrm{t})$ & 68756 \\
\hline Pitch/roll gyration radius $(\mathrm{m})$ & 68.47 \\
\hline CG above keel $(\mathrm{m})$ & 83.57 \\
\hline CB above keel $(\mathrm{m})$ & 89.82 \\
\hline$G M_{0}(\mathrm{~m})$ & 8.66 \\
\hline Average draft $(\mathrm{m})$ & 151.6 \\
\hline Water depth $(\mathrm{m})$ & 1500 \\
\hline
\end{tabular}

coefficient, and the damping ratio is identified through the free-decay simulation based on the coupled model.

The main object of this paper is to indicate how the damping affects the Mathieu instability of DDMS platform. Firstly, the hydrodynamic theories adopted in this paper are reviewed briefly. Secondly, the complex coupled heave and pitch equations are presented. Thirdly, the damping ratios are identified from the free-decay tests and six damping cases are generated. Then, the coupled heave and pitch equations are solved by using the 4th order Runge-Kutta method with damping cases under five regular waves of different wave heights and periods. Finally, the stability of DDMS under four random conditions is investigated and the simulation results distinctly reveal that the DDMS platform does not suffer from the Mathieu instability even in theses extreme environments.

\section{INTRODUCTION OF DDMS PLATFORM}

The design advantages of DDMS platform are less construction difficult, larger topside space, dry tree availability, and favorable motion performance. The platform in this paper can support 10000t's payloads and 7730t's steel weight of topside structure, and is designed under condition of 100year return period of GOM by using an interactive design method. The structural components and characteristic dimensions as well as mass information for DDMS are shown in Fig. 1(a) and Table 1. The hard tank is composed of four columns at corners and a novel moonpool protecting the top tension risers at the center. It is noted that the top tension and selfweight of rigid risers are provided by air-cans. At the foot of hard tank, the pontoons and horizontal bracing are used to connect the separated columns and moonpool. In order to decrease the heave motion, two heave plates directly integrated with the hard tank are expected to excite viscous damping vertically and to attract more heave added mass to keep the heave natural period away from the wave frequency (W-F) controlled area. The middle section of the platform consists of 


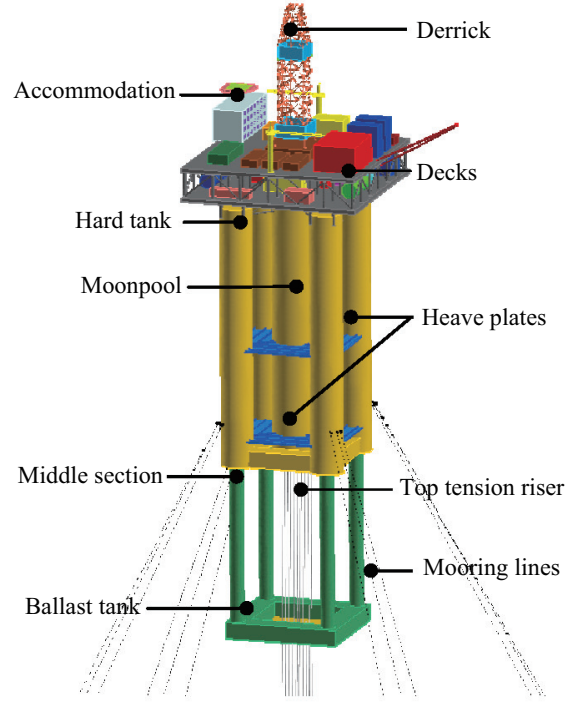

(a)

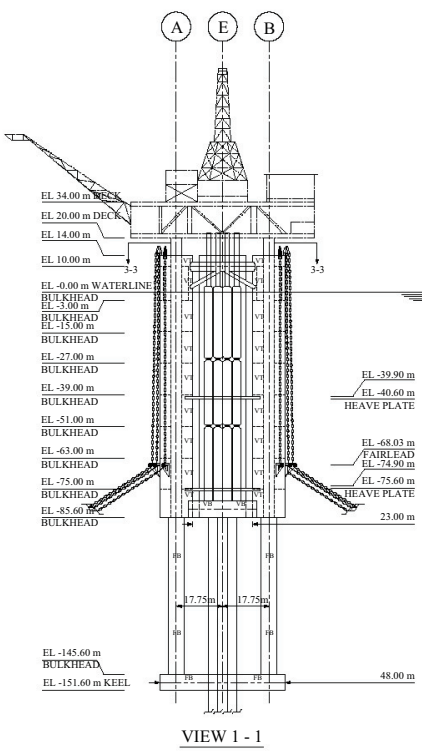

VIEW 1 -

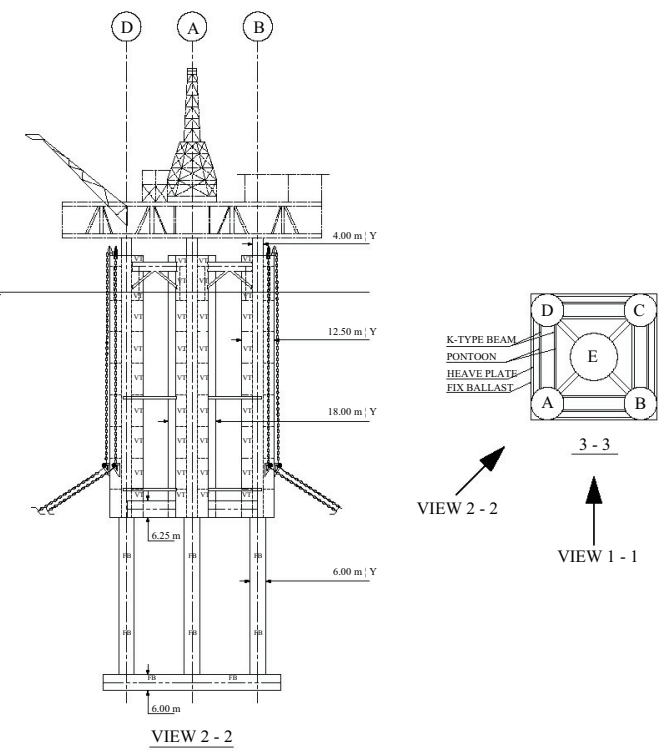

(b)

Fig. 1. (a) Main Components of DDMS concept, (b) DDMS dimensions and overall layout.

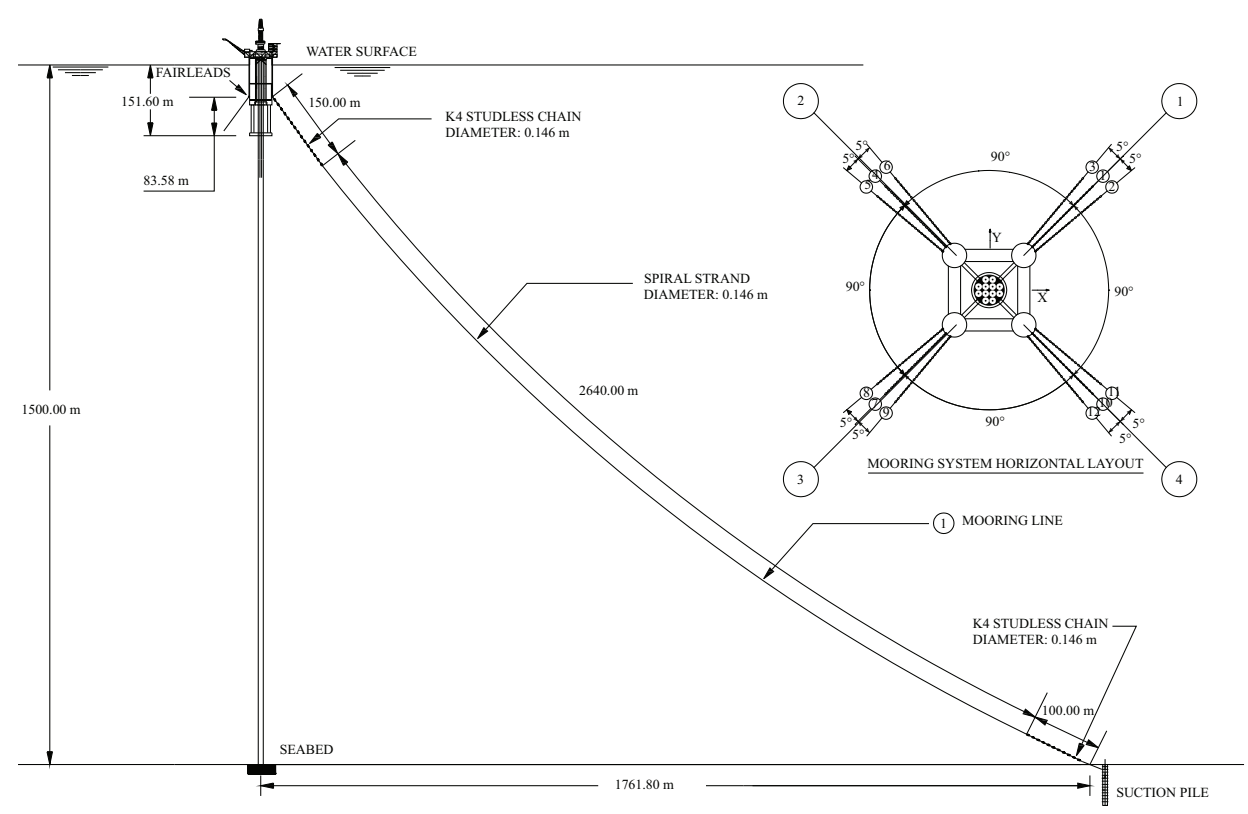

Fig. 2. Mooring system configuration.

4 columns of smaller diameter which connect the hard tank and ballast tank. The DDMS concept ensures the centre of gravity (CG) below the centre of buoyancy (CB) to acquire perfect stability, so the ballast tank at the bottom is full of high density fluid or metals. The compartments and general layout is shown in Fig. 1(b). The DDMS platform applies 12 mooring lines to keep the position, and all the lines are separated into 4 groups and symmetrically arranged on the four columns. Each group is $90^{\circ}$ from another and the lines of each group are $5^{\circ}$ azimuth spread. Each line makes up of an upper chain section, a middle cable section and a ground chain section. The general configuration of mooring system is illustrated in Fig. 2.

\section{CALCULATIONAL THEORY}

\section{Hull Hydrodynamics}

The wave action on the floating structure is generally calculated by using the potential flow theory. Meanwhile, we make assumptions that the fluid is irrotational, inviscid and incompressible. The fluid needs to satisfy the Laplace's equation: 


$$
\nabla^{2} \Phi^{(1)}=\frac{\partial^{2} \Phi}{\partial x^{2}}+\frac{\partial^{2} \Phi}{\partial y^{2}}+\frac{\partial^{2} \Phi}{\partial z^{2}}=0
$$

where $\Phi^{(1)}$ is 1 st order total velocity potential function involving incident potential $\Phi_{I}^{(1)}$, diffraction potential $\Phi_{D}^{(1)}$ and radiation potential $\Phi_{R}^{(1)}$. In order to solve the potential function $\Phi^{(1)}$, some boundary conditions below are applied

$$
\begin{array}{cr}
\left(-\omega^{2}+g \frac{\partial}{\partial z}\right) \Phi_{D, R}^{(1)}=0 & \text { free surface }(z=0) \\
\frac{\partial \Phi_{D, R}^{(1)}}{\partial z}=0 & \text { seabed }(z=-d) \\
\frac{\partial \Phi_{D}^{(1)}}{\partial n}=-\frac{\partial \Phi_{I}^{(1)}}{\partial n} & \text { body surface } \\
\frac{\partial \Phi_{R}^{(1)}}{\partial n}=-\mathrm{i} \omega \mathbf{n} \cdot\left(\xi^{(1)}+\boldsymbol{\alpha}^{(1)} \times \mathbf{r}\right) & \text { body surface } \\
\lim _{r \rightarrow \infty} \sqrt{r}\left(\frac{\partial}{\partial r} \pm i k\right) \Phi_{D, R}=0 & \text { at far field }
\end{array}
$$

where $\mathbf{n}, \mathbf{r}$ and $d$ denote the outward unit normal vector at the body surface, position vector on the body surface and water depth. $\xi^{(1)}$ and $\boldsymbol{\alpha}^{(1)}$ are translational and rotational first order of floater. Once the potential function $\Phi^{(1)}$ is solved, the exciting wave forces and moments can be obtained by direct integration over the wetted body surface

$$
F_{E X i}^{(1)}= \begin{cases}\operatorname{Re}\left[-\rho A e^{\mathrm{i} \omega t} \iint_{S_{b}} n_{i}\left(\Phi_{I}+\Phi_{D}\right) d S\right] & (i=1,2,3) \\ \operatorname{Re}\left[-\rho A e^{\mathrm{i} \omega t} \iint_{S_{b}}(\mathbf{r} \times \mathbf{n})_{i}\left(\Phi_{I}+\Phi_{D}\right) d S\right] & (i=4,5,6)\end{cases}
$$

where $S_{b}$ and $A$ express the wetted body surface and wave amplitude. $i=1, \ldots, 6$ denote the models i.e. surge, sway, heave, roll, pitch and yaw. The frequency-dependent added mass and radiation damping coefficient matrixes are acquired below

$$
\mathbf{F}_{\mathbf{R}}^{(\mathbf{1})}=\operatorname{Re}\left(\left[\mathbf{M}^{a}\right]\left\{\ddot{\boldsymbol{\zeta}}^{(1)}\right\}+[\mathbf{C}]\left\{\dot{\boldsymbol{\zeta}}^{(1)}\right\}\right)
$$

where $\mathbf{M}^{a}$ and $\mathbf{C}$ are added mass and damping matrixes. $\quad \mathbf{F}_{\mathbf{R}}^{(\mathbf{1})}$ is radiation force vector and calculated by using radiation potential $\Phi_{R}^{(1)}$.

For the hard tank, pontoons and ballast tank of large dimensions, the hydrodynamic information are calculated by using above potential theory through the high order boundary element method (HOBEM).
The middle section composed of columns, is simulated as elements of Morison type considering the drag and inertial force due to its small diameter compared with the wave length. The Morison force on each element is expressed below

$$
F_{M r}=C_{I} \rho \frac{\pi D^{2} l_{s c}}{4} \dot{u}-C_{a} \rho \frac{\pi D^{2} l_{s c}}{4} \ddot{x}+\frac{1}{2} \rho C_{d} D l_{s c}(u-\dot{x})|(u-\dot{x})|
$$

where $C_{I}=C_{a}+1$ is inertia force coefficient, $C_{a}, C_{d}, D$ and $l_{s c}$ denote added mass coefficient, drag coefficient, diameter and length. $u$ and $\dot{x}$ express the fluid and platform velocities. For the heave plates, due to its extraordinary thin thickness, some special disc elements with no thickness and mass are used to represent the added mass and drag forces

$$
F_{m r}=\frac{8}{3} \rho C_{a} r_{H P}^{3} \ddot{y}+\frac{1}{2} \rho C_{d} \pi r_{H P}^{2} \dot{y}|\dot{y}|
$$

where $r_{H P}$ and $\dot{y}$ are disc radius and vertical velocity. In addition, the viscous damping induced by hard tank, significantly limiting the low-frequency responses near the natural periods for degrees of freedom of horizontal plane, is represented by drag force and estimated by integrating the Morison drag item

$$
F_{h d}=\int_{0}^{h} \frac{1}{2} \rho C_{d} D_{h} U|U| \mathrm{d} l
$$

where $U, D_{h}$ and $h$ are relative velocity, diameter and height for hard tank respectively.

In the analysis of random wave action, the wave elevation of time history is generated through a number of linear waves

$\eta(t, \mathbf{x})=\sum_{i=1}^{N} A_{i} \cos \left(\mathbf{k}_{i} \mathbf{x}-\omega_{i} t+\varepsilon_{i}\right)=\operatorname{Re}\left[\sum_{i=1}^{N} A_{i} e^{\mathrm{i}\left(\mathbf{k}_{i} \mathbf{x}-\omega_{i} t+\varepsilon_{i}\right)}\right]$

where $N, \mathbf{k}_{j}, \Delta \omega$ and $\varepsilon_{i}$ are wave component number, wave number, frequency interval and random phase from $0 \sim 2 \pi . A_{i}$ denotes the wave amplitude component and determined by the formula below

$$
\sqrt{2 S_{\eta}\left(\omega_{i}\right) \Delta \omega}
$$

where $S_{\eta}\left(\omega_{i}\right)$ expresses the wave spectrum. Similar to the random wave elevation, the 1 st order wave exciting force is captured

$$
\mathbf{F}_{W F}^{(\mathbf{1})}=\operatorname{Re}\left[\sum_{i=1}^{N} A_{i} \mathbf{L}\left(\omega_{i}\right) e^{\mathrm{i}\left(\mathbf{k}_{i} \mathbf{x}-\omega_{i} t+\varepsilon_{i}\right)}\right]
$$

where $\mathbf{L}\left(\omega_{i}\right)$ indicates the linear transfer function of wave 
force which is obtained from previous hydrodynamic calculation.

\section{Mooring Line Dynamics}

Accurately assessing the hydrodynamic damping and the tension of mooring line through dynamic approach is important not only for the hull motion mentioned above, but also for the reliable design of mooring lines. The analytical strategy of mooring dynamics in this paper disperses the cable into a certain amount of elements which is calculated in local coordinate system and accounting for some non-linear factors e.g. drag and inertial forces. It is noted that the seabed frictions and bending stiffness are ignored. The element motion equation is as following

$$
\left(M_{m}+M_{m a}\right) A_{m}=F_{g}+F_{b}+F_{d}+F_{s}
$$

where $M_{m}, M_{m a}$ and $A_{m}$ denote the structural mass, added mass matrixes $(6 \times 6)$ and acceleration vector $(6 \times 1) ; F_{g}, F_{b}, F_{d}$ and $F_{s}$ are gravity force, buoyancy force, drag force and seabed reaction vectors $(6 \times 1)$ respectively. In fact the equation above has 6 degrees of freedom for 2 nodes of an element, and each node has 3 including the inline and 2 normal directions. In calculation process of coupled hull and mooring lines, the total mooring line force should be instantaneously shifted to the platform reference point i.e. center of gravity by using transfer matrix

$$
\begin{gathered}
\mathbf{P}_{g}=\left(\begin{array}{c}
\mathbf{I} \\
\mathbf{T}_{a}^{T}
\end{array}\right) \mathbf{P}_{a}=\left(\begin{array}{c}
\mathbf{P}_{a} \\
\mathbf{T}_{a}^{T} \mathbf{P}_{a}
\end{array}\right) \\
\mathbf{P}_{a}=\left(\begin{array}{ccc}
0 & P_{z} & -P_{y} \\
-P_{z} & 0 & P_{x} \\
P_{y} & -P_{x} & 0
\end{array}\right), \mathbf{T}_{a}=\left(\begin{array}{ccc}
0 & z & -y \\
-z & 0 & x \\
y & -x & 0
\end{array}\right)
\end{gathered}
$$

where $\mathbf{P}_{g}$ and $\mathbf{P}_{a}$ are force matrix at CG of platform and fairlead respectively. $P_{x}, P_{y}$ and $P_{z}$ are mooring line force components for $x, y$ and $z$ at fairlead, and $\mathbf{T}_{\mathrm{a}}$ denote transfer matrix. In time domain simulation, tension for mooring line and the motion of hull are considered to be mutually interactive where the mooring line effects hull motion.

\section{Coupled Heave and Pitch Equations}

Generally, The hydrostatic stiffness is regarded as a constant value from the static equilibrium position and has a linear relationship with corresponding restoring force. However, the vertical motion is always accompanied by the rotational motion at the same time when the platform undergoes wave actions. Thus, the hydrostatic stiffness changes with the global platform motions and the restoring forces are time-varying actually. According to the geometrical relation of vertical and rotation motion, the complete express of heave restoring force $R_{3}$ is

$$
\begin{aligned}
R_{3}= & \left(x_{3}(t)-\eta(t)\right) \rho g A_{w} \sqrt{1+\tan ^{2} x_{4}(t)+\tan ^{2} x_{5}(t)} \\
& -\rho g A_{w} H_{g}\left(\sqrt{1+\tan ^{2} x_{4}(t)+\tan ^{2} x_{5}(t)}-1\right)
\end{aligned}
$$

where $x_{3}, x_{4}$ and $x_{5}$ are heave displacement, roll and pitch angles, and $\eta, A_{w}$ and $H_{g}$ denote the wave elevation, waterline area and distance from water surface to the CG point respectively. The first item of above formula indicates the contribution considering the change of waterline area due to the rotation motion; the second item indicates the contribution of platform vertical motion induced by the rotation response. For analytical convenience, Eq. (14) can be simplified to a plane problem based on the double axis symmetry of DDMS platform and consequently the roll motion $x_{4}$ disappears. Further more, the wave elevation is neglected and finally the Eq. (14) is simplified below

$$
R_{3}=x_{3} \rho g A_{w} \alpha-\rho g A_{w} H_{g}(\alpha-1)
$$

where $\alpha=\sqrt{1+\tan ^{2} x_{5}(t)}$.

Similar to the change of $R_{3}$ with the rotational motion, pitch restoring force $R_{5}$ varies with heave motion $x_{3}$ because the metacentric height $G M$ and displaced volume $\forall$ relate to vertical response. The time-varying metacentric height as well as displacement volume are derived below

$$
\begin{gathered}
G M=G M_{0}-0.5\left[x_{3}(t)-\left(H_{g}-x_{3}(t)\right)(\alpha-1)\right] \\
\forall=\forall_{0}-A_{w}\left[x_{3}(t)-\left(H_{g}-x_{3}(t)\right)(\alpha-1)\right]
\end{gathered}
$$

where $G M_{0}$ and $\forall_{0}$ are the initial metacentric height and initial displaced volume at static equilibrium position. Therefore, the corresponding restoring force $R_{5}$ considering the varying of metacentric height and displaced volume is expressed by following formula

$$
\begin{aligned}
R_{5}= & x_{5}(t) \rho g \forall G M=x_{5}(t)\left[\rho g \forall_{0} G M_{0}\right. \\
& -0.5 \rho g\left(\forall_{0}+2 A_{w} G M_{0}\right)\left(x_{3}(t)-\left(H g-x_{3}(t)\right)(\alpha-1)\right) \\
& \left.+0.5 \rho g A_{w}\left(x_{3}(t)-\left(H g-x_{3}(t)\right)(\alpha-1)\right)^{2}\right]
\end{aligned}
$$

According to Newton's second law, the motion equations of coupled heave and pitch accounting the varying restoring force can be expressed below simply

$$
\left\{\begin{array}{l}
\left(M_{s}+m_{33}\right) \ddot{x}_{3}+C_{3} \dot{x}_{3}+R_{3}\left(x_{3}, x_{5}\right)=F_{3}(t) \\
\left(I_{55}+m_{55}\right) \ddot{x}_{5}+C_{5} \dot{x}_{5}+R_{5}\left(x_{5}, x_{3}\right)=M_{5}(t)
\end{array}\right.
$$

where $M_{s}, m_{33}, C_{3}, F_{3}$ and $x_{3}$ denote the platform mass, added 


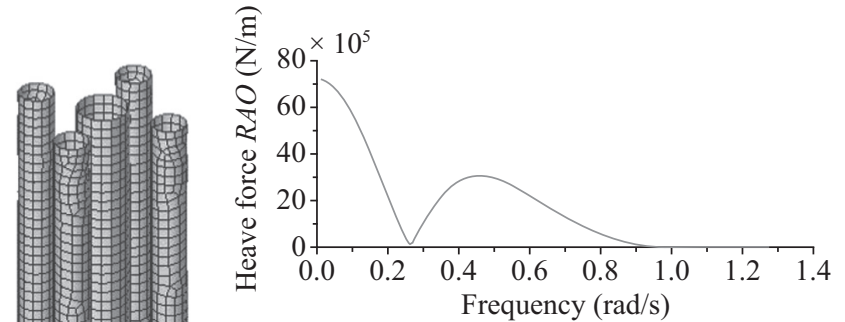

(b)

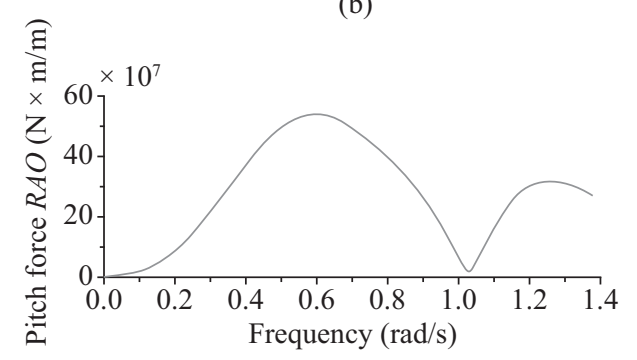

(a)

(c)

Fig. 3. (a) Panel model, (b) heave force $R A O$, (c) pitch force $R A O$.

mass, damping coefficient, external force and heave displacement; $I_{55}, m_{55}, C_{5}, M_{5}$ and $x_{5}$ represent the pitch moment of inertia, added mass, damping coefficient, external moment and pitch angle. To evaluate the non-linear heave and pitch damping effects, free-decay tests are executed based on the hydrodynamic predicting method and coupled hull and mooring model in previous section. The relevant free-decay results are summarized in the next section.

\section{NUMERICAL CALCULATION AND RESULTS ANALYSIS}

\section{Hydrodynamic Performance of DDMS Platform}

Based on the hull hydrodynamic theory described in previous section, the 1st order hydrodynamic information as well as the motion $R A O$ s are obtained. The wave incident angle is zero i.e. along the positive direction of $x$ axis, and all the results are regarded to CG point. Fig. 3(a) illustrates the panel model of DDMS platform, and heave and pitch force $R A O \mathrm{~s}$ representing the HOBEM's calculated results are shown in Figs. 3(b) and 3(c).

The RAOs for heave, pitch and surge are drawn in Fig. 4. This figure distinctly displays that the surge and pitch responses in W-F region are relative small and the curves vary smoothly. Thereby, the 1st order responses excited by waves can be effective filtered and reduced. It concludes that the surge and pitch's motion performances are favorable. As for heave, the figure shows the natural period is greater than $30 \mathrm{~s}$ which is even higher than the natural period of traditional Spar platform. This is because the smaller waterline area for DDMS platform compared with that of the Spar. We also observe that the heave $R A O$ curve maintains a relative low magnitude and varies smoothly till the cancellation period at around $25 \mathrm{~s}$. For common wave condition of 100-year return

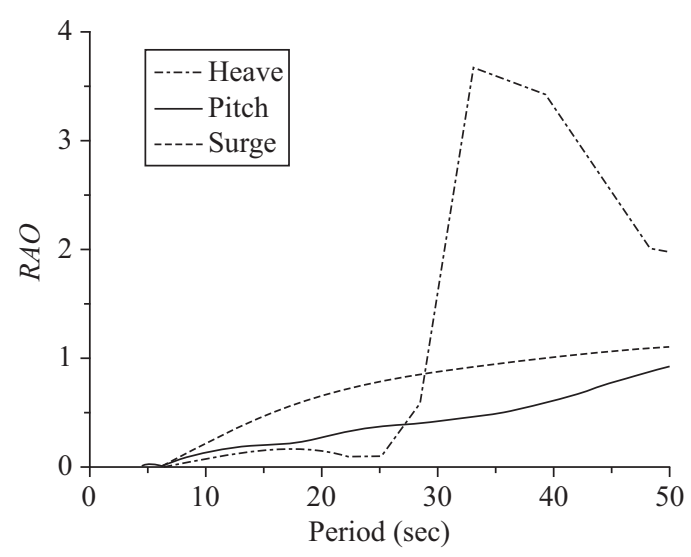

Fig. 4. Response $R A O$ s for heave, pitch and surge.

period with peak period of 12 16 s, the deep draft platforms such as DDMS and Spar have the ability to guarantee the relative low extreme heave response. However for some special wave cases e.g. swell wave, the peak period can exceed $20 \mathrm{~s}$ which is close to the heave natural period, and large resonant heave response may be excited. Meanwhile, we find out from Fig. 4 that the heave response is nearly 4 times of incident wave amplitude at natural period. Similarly in experiment executed by Rho et al. [10], the measured value of heave $R A O$ at natural period even exceeds 8 . The large heave response causes the hydrostatic parameters e.g. metacentric height and displaced volume inconstant and may lead to instable pitch motion. Therefore, it is significant and necessary to investigate coupled heave and pitch motions by considering the time-varying restoring forces especially for the novel DDMS platform.

\section{Damping Identification}

The damping contribution and natural period of DDMS platform are identified through the free-decay test based on the hull/mooring coupled method in previous section. As for heave, platform models with/without heave damping and with coupled mooring line damping are conducted. The relevant information involving structural dimensions and hydrodynamic coefficient for mooring line are summarized in Table 2. For pitch, the hull drag coefficients $C_{d}$ and mooring line damping determine the linear damping ratio. The free-decay tests are plotted in Fig. 5. In order to distinctly and effectively reflect the damping effects on the Mathieu instability, these identified results generate an analytical matrix of 6 damping cases which are listed in Table 3. The first three cases have identical pitch damping ratio with 0.1 drag coefficient while different heave damping ratios to assess the influence of heave motion to the Mathieu instability. It is noted that the $0.41 \%$ pitch damping ratio does not match the $5.78 \%$ heave damping ratio for Case 3 because in which the coupled effects are assumed to be applied to the heave only to compare with other cases. Case 4 and Case 5 have different pitch damping ratios, however same heave damping ratio without mooring coupled. 
Table 2. Mooring line properties.

\begin{tabular}{|c|c|c|c|c|c|}
\hline Section & $\begin{array}{c}\text { Dry/wet weight } \\
(\mathrm{kg} / \mathrm{m})\end{array}$ & $\begin{array}{c}\text { Diameter } \\
(\mathrm{m})\end{array}$ & $\begin{array}{c}\text { Length } \\
(\mathrm{m})\end{array}$ & $C_{a}$ & $C_{d}$ \\
\hline Upper & $443 / 385.6$ & 0.146 & 159 & 2.2 & 2.0 \\
\hline Middle & $90.8 / 78.5$ & 0.146 & 2640 & 1.8 & 1.0 \\
\hline Ground & $443 / 385.6$ & 0.146 & 100 & 2.2 & 2.0 \\
\hline
\end{tabular}

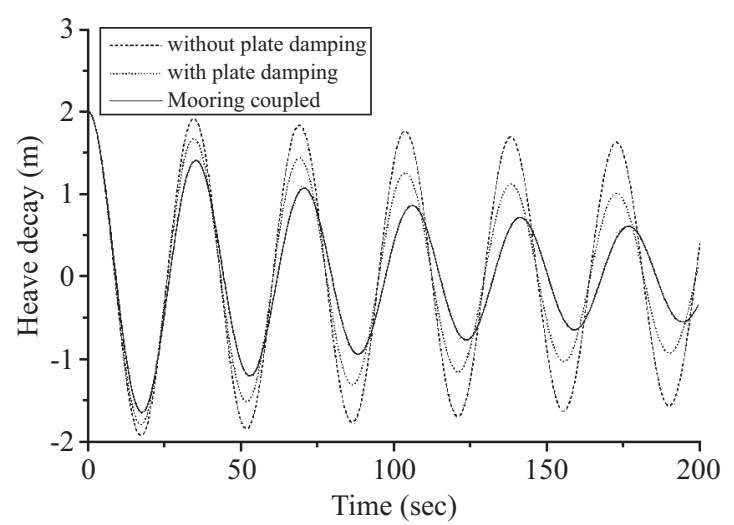

(a)

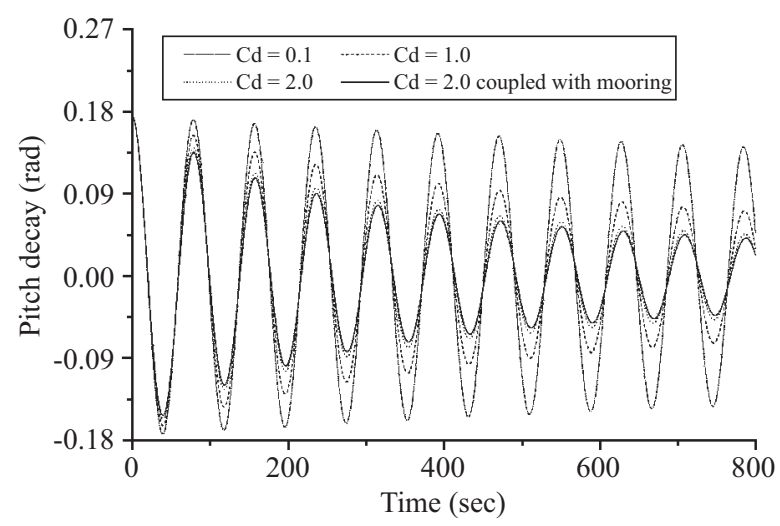

(b)

Fig. 5. (a) Heave decay curves, (b) pitch decay curves.

Case 6 have $3.11 \%$ and $5.78 \%$ heave and pitch damping ratios with maximum 2.0 drag coefficient and mooring coupled. The drag coefficients selected in this paper are within the general empirical range, and the corresponding identified pitch damping are within acknowledged range 1 4\% [3]. In addition, the natural periods of heave and pitch are $34.6 \mathrm{~s}$ and 78.2 $\mathrm{s}$ respectively through the free-decay tests.

\section{Regular Wave Action}

In this section, 5 different regular waves of different heights $(H)$ and periods $(T)$ tabulated in Table 4 act on the coupled heave and pitch model with damping cases in previous section. The wave periods cover the range from heave natural period to half pitch natural period. RW-1 and RW-2 have identical 32.6 $\mathrm{s}$ wave period which is close to the $34.6 \mathrm{~s}$ heave natural period, and RW-3 and RW-4 have $34.6 \mathrm{~s}$ and $36.6 \mathrm{~s}$ periods which are
Table 3. Damping cases.

\begin{tabular}{|c|c|c|c|c|}
\hline Case & $\begin{array}{c}\text { Pitch/heave } \\
\text { damping ratio }\end{array}$ & $C_{d}$ & $\begin{array}{c}\text { Heave plate } \\
\text { damping }\end{array}$ & $\begin{array}{c}\text { Coupled } \\
\text { model }\end{array}$ \\
\hline Case 1 & $0.41 \% / 1.45 \%$ & 0.1 & $\mathrm{~N}$ & $\mathrm{~N}$ \\
\hline Case 2 & $0.41 \% / 4.0 \%$ & 0.1 & $\mathrm{Y}$ & $\mathrm{N}$ \\
\hline Case 3 & $0.41 \% / 5.78 \%$ & 0.1 & $\mathrm{Y}^{*}$ & $\mathrm{Y}$ \\
\hline Case 4 & $1.86 \% / 4.0 \%$ & 1.0 & $\mathrm{Y}$ & $\mathrm{N}$ \\
\hline Case 5 & $2.87 \% / 4.0 \%$ & 2.0 & $\mathrm{Y}$ & $\mathrm{N}$ \\
\hline Case 6 & $3.11 \% / 5.78 \%$ & 2.0 & $\mathrm{Y}$ & $\mathrm{Y}$ \\
\hline
\end{tabular}

* In Case 3, the coupled effects are assumed to be reflected to the heave damping only.

Table 4. Regular wave cases.

\begin{tabular}{|c|c|c|c|c|c|}
\hline & RW-1 & RW-2 & RW-3 & RW-4 & RW-5 \\
\hline$H(\mathrm{~m})$ & 6 & 8 & 3 & 2 & 2 \\
\hline$T(\mathrm{sec})$ & 32.6 & 32.6 & 34.6 & 36.6 & 39.1 \\
\hline
\end{tabular}

Table 5. Statistic of maximum responses.

\begin{tabular}{|c|c|c|c|c|}
\hline $\begin{array}{c}\text { Wave } \\
\text { case }\end{array}$ & Damping case & $\begin{array}{c}\text { ABS Max } \\
\text { heave (m) }\end{array}$ & $\begin{array}{c}\text { ABS Max } \\
\text { Pitch }\left(^{\circ}\right.\end{array}$ & $\begin{array}{c}\text { STD } \\
\left({ }^{\circ}\right)\end{array}$ \\
\hline \multirow{4}{*}{ RW-1 } & Case 1 & 22.10 & 35.81 & 13.8 \\
\cline { 2 - 5 } & Case 2 & 11.08 & 2.52 & 0.68 \\
\cline { 2 - 5 } & Case 4 & 11.07 & 1.84 & 0.44 \\
\hline \multirow{4}{*}{ RW-2 } & Case 2 & 16.08 & 29.47 & 14.72 \\
\cline { 2 - 5 } & Case 3 & 11.91 & 4.77 & 1.04 \\
\cline { 2 - 5 } & Case 4 & 15.54 & 27.49 & 14.35 \\
\cline { 2 - 5 } & Case 5 & 15.20 & 25.99 & 14.03 \\
\hline \multirow{3}{*}{ RW-3 } & Case 6 & 11.90 & 2.40 & 0.58 \\
\cline { 2 - 5 } & Case 4 & 10.43 & 13.10 & 6.41 \\
\cline { 2 - 5 } & Case 5 & 10.50 & 12.13 & 6.05 \\
\hline \multirow{2}{*}{ RW-4 } & Case 6 & 7.43 & 0.54 & 0.20 \\
\cline { 2 - 5 } & Case 5 & 5.64 & 3.61 & 1.92 \\
\hline RW-5 & Case 6 & 4.50 & 0.37 & 0.14 \\
\hline
\end{tabular}

close to the half pitch natural period of $78.2 \mathrm{~s}$. RW-5 is special, for the wave period equals to $39.1 \mathrm{~s}$ which is just the half pitch natural period and most possible to excite the Mathieu instability theoretically.

Figs. 6(a) 6(j) show the heave and pitch response under RW-1, and the absolute maximum response values and standard deviations of corresponding pitch spectra are listed in Table 5 for all calculated cases. In Figs. 6(a) and 6(b), the tremendous heave motion of Case 1 is excited due to the small $1.45 \%$ heave damping ratio and surely triggers the Mathieu instability. The corresponding pitch motion is very large even up to the peak value of $35.81^{\circ}$ and finally becomes stable after 


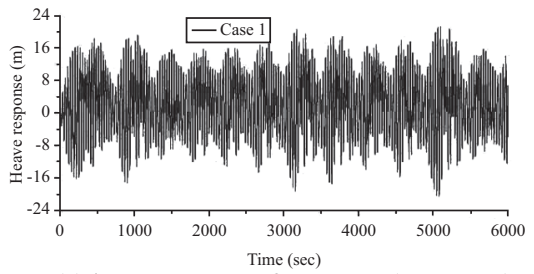

(a) heave response for Case $1(0 \mathrm{~s} \sim 8000 \mathrm{~s})$

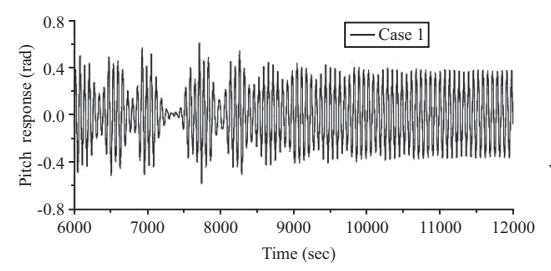

(d) pitch response for Case 1 (8000 s 12000 s)

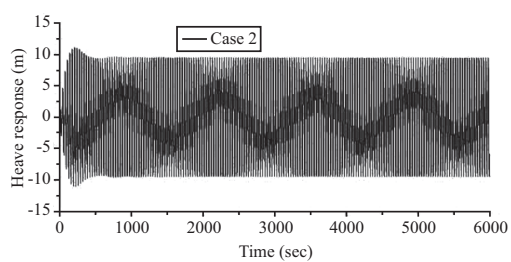

(g) heave response for Case 2

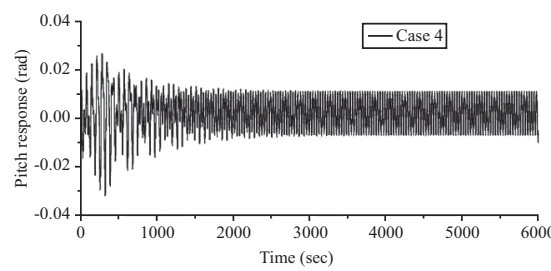

(j) pitch response for Case 4

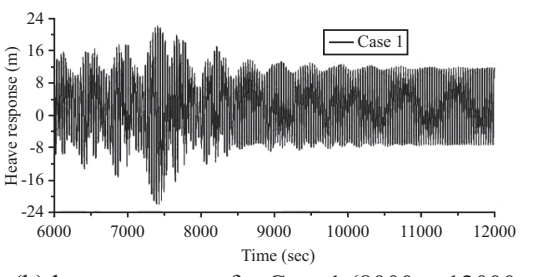

(b) heave response for Case $1(8000 \mathrm{~s} \sim 12000 \mathrm{~s})$

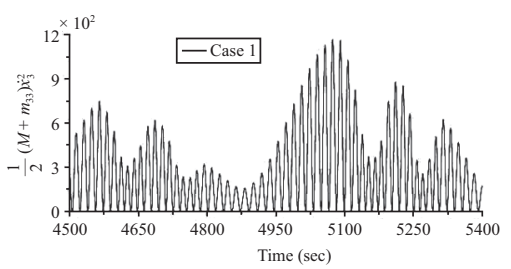

(e) heave renergy for Case 1

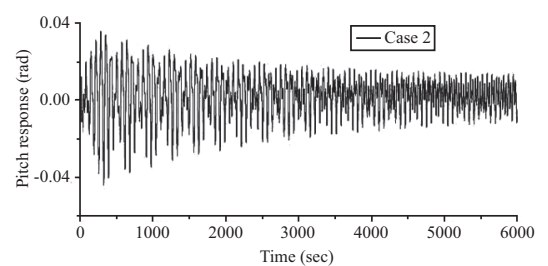

(h) pitch response for Case 2

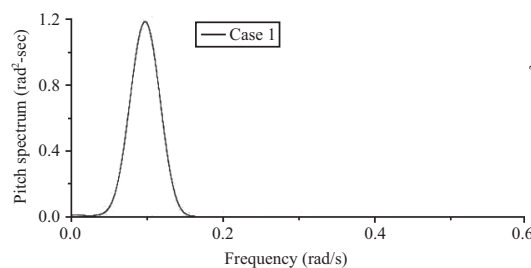

(k) pitch spectrum

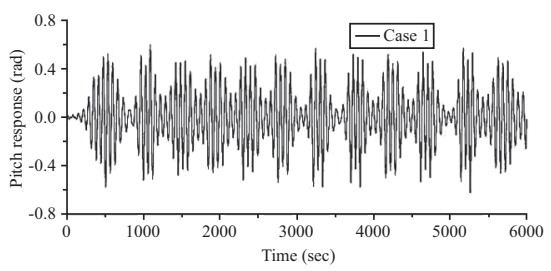

(c) pitch response for Case $1(0 \mathrm{~s} \sim 8000 \mathrm{~s})$

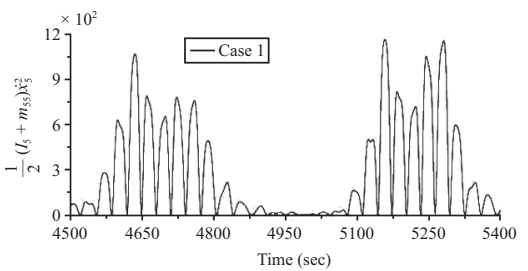

(f) pitch energy for Case 1

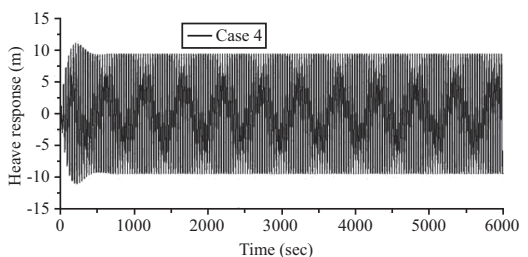

(i) heave response for Case 4

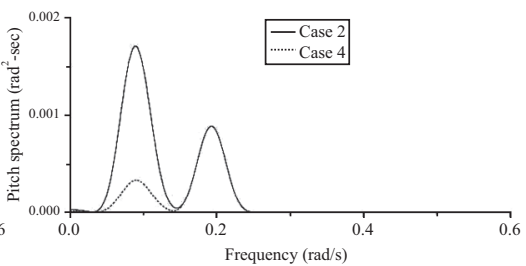

(1) pitch spectra

Fig. 6. Calculated results under RW-1.

$10000 \mathrm{~s}$. The stable in this paper means the heave or pitch motion oscillates with a certain frequency and amplitude. However under the condition of 100-year return period, the maximum peak response normally does not exceed $10^{\circ}$ without considering the coupled heave and pitch. In addition, the large pitch motion also makes the heave unstable, and an observation obviously shows the two coupled motions increase and decrease turn by turn e.g. motions around $5000 \mathrm{~s}$ and 7400 s. This phenomena is owing to the energy transfer alternately between the heave and pitch, and furthermore the time-energy shown in Figs. 6(e) and 6(f) have powerfully proved this viewpoint. Case 2 does not have Mathieu instability because of the viscous damping from the heave plates, and the pitch motion with a peak value of $2.52 \mathrm{~m}$ tardily decays and trends to be stable. It is worth noting that the pitch peak value ratio between Case 1 and Case 2 is 14.2, and this remarkable issue is essentially caused by the pitch restoring stiffness nearly zero or negative due to large heave response. Case 4 having identical heave damping ratio with Case 2 is executed under RW-1, the result indicates that the increase of pitch damping accelerates the pitch motion stability. The pitch response spectra of RW-1 are shown in Figs. 6(k) and 6(1).
The heave and pitch motions as well as pitch spectra under RW-2 are plotted in Fig. 7. In analysis of the RW-1 action, the damping level of Case 2 is adequate to resist the instability happening under $6 \mathrm{~m}$ wave height, thereby, in RW-2 the wave height increases while the period is consistent. The Figs. 7(a) and 7(b) show Case 2 has Mathieu instability and a large pitch response is induced. This is because the damping is not enough, and the pitch instability in Case 2 is much different from the one in Case 1 under RW-1. The pitch motion increases soon and reaches the peak at $700 \mathrm{~s}$, and quickly becomes stable after a transitory energy exchange with heave response. The similar phenomena are observed in Case 4 and Case 5, but owing to the increase of pitch damping, the pitch peak values and general responses slightly decrease which are shown by the spectra in Fig. 7(k) and statistics in Table 5. Case 3 and Case 6 does not trigger the Mathieu instability because the heave response is effectively suppressed by the heave damping ratio which is 1.45 times of those for Case 2, 4 and 5. The simulated results reveal that the heave damping accounting for the mooring contribution based on the coupled method significantly determines the occurrence of Mathieu instability. Therefore, neglecting or underestimating the 


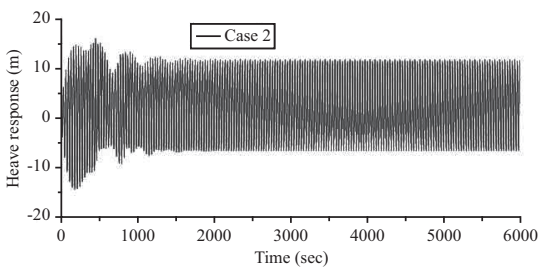

(a) heave response for Case 2

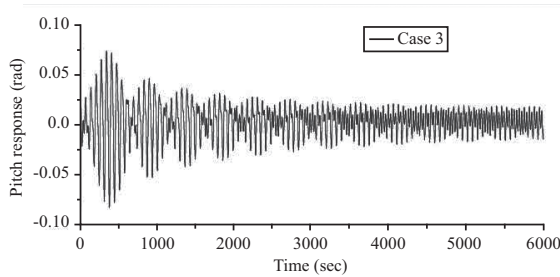

(d) pitch response for Case 3

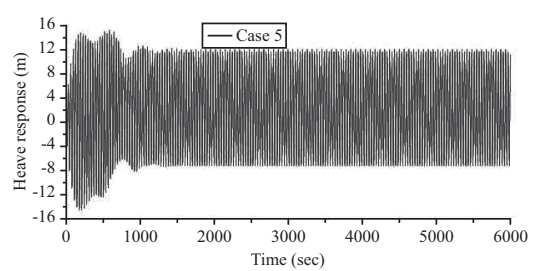

(g) heave response for Case 5

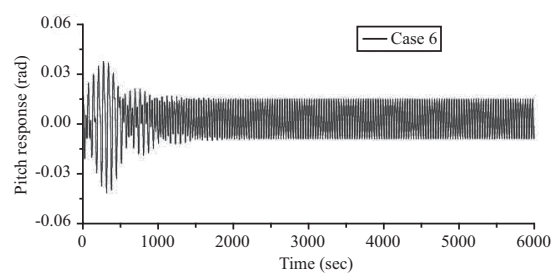

(j) pitch response for Case 6

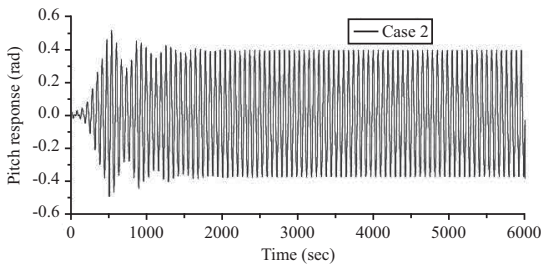

(b) pitch response for Case 2

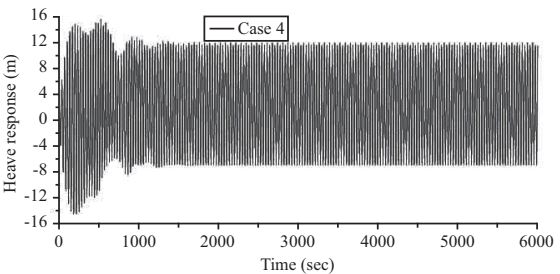

(e) heave response for Case 4

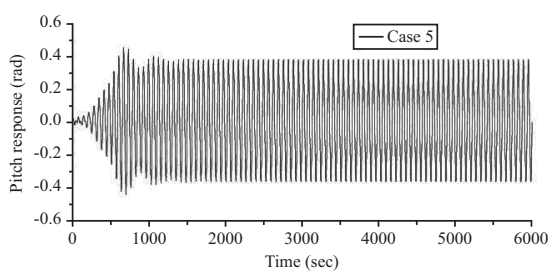

(h) pitch response for Case 5

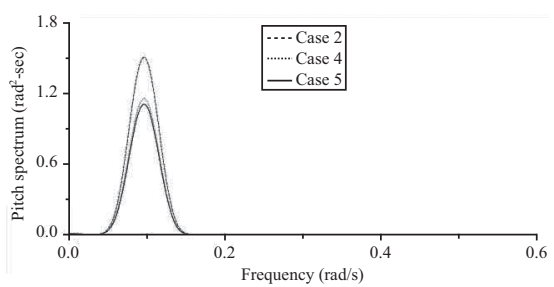

(k) pitch spectra

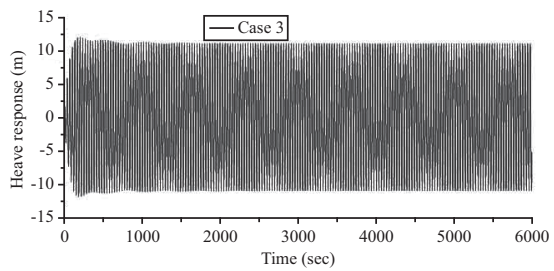

(c) heave response for Case 3

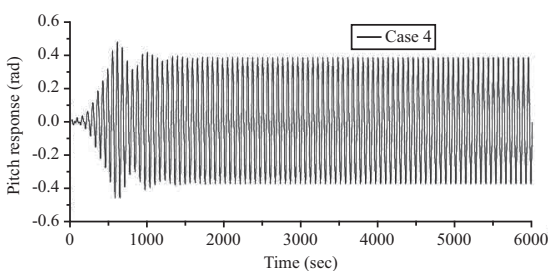

(f) pitch response for Case 4

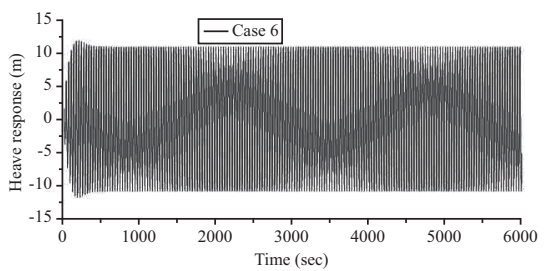

(i) heave response for Case 6

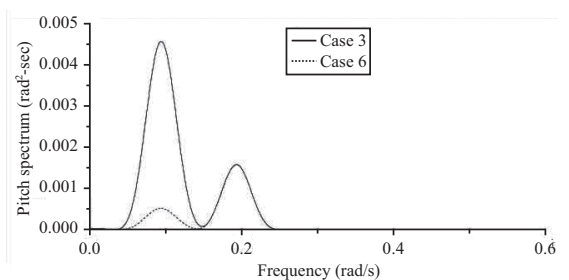

(1) pitch spectra

Fig. 7. Calculated results under RW-2.

mooring damping may cause the coupled motions conservative.

Coupled motions under RW-3 are shown in Figs. 8(a) 8(f) as well as the pitch spectra in Figs. $8(\mathrm{~g})$ and $8(\mathrm{~h})$. The simulated results indicate that Case 4 and Case 5 have Mathieu instability, and this type of pitch instability is similar with the one under RW-2, however, the pitch peak values appear latterly and the energy exchange becomes gentle. Figs. 8(e) and $8(f)$ clearly shows the Case 6 has no energy transfer between heave and pitch.

Figs. 9(a) 9(d) plot the coupled motions of Case 5 and Case 6 under RW-4, and the Figs. 9(e) and 9(f) show the Case 6 under RW-5. The pitch response spectra are drawn in Figs. $9(\mathrm{~g})$ and 9(h). For Case 5 as shown in Fig. 9(b), this pitch instability is different from the previous two types. The heave response tardily decreases while the pitch motion gradually and gently increases until becoming stable after $3200 \mathrm{~s}$. Mathieu instability is not observed in Case 6 under RW-4 but is triggered in Case 6 under RW-5 in despite of the same $2 \mathrm{~m}$ wave height of the two regular waves. In addition, the maximum heave response of Case 6 under RW-5 is $3.76 \mathrm{~m}$ as shown in Table 5, although which is significantly smaller than those of this case under other regular waves previously, and the instability is still excited. The reason is the wave period which is just the half of the pitch natural period. Therefore, in this wave type, the Mathieu instability easily happens even with the damping of top level. Figs. 9(e) and 9(f) show an interesting phenomena that comparing the Figs. 9(c) and 9(d), the heave motion distinctly transfers and contributes its energy to pitch, and it is just the transferred energy leads to the pitch instability. Pitch motions from $0 \sim 2000 \mathrm{~s}$ of Case 6 under RW-4 and RW-5 are plotted in Fig. 10, and from which the secrete of pitch instability could be explained. For Case 6 under RW-4, two different adjacent motions appear and gradually dissipate, finally, steadily oscillate with wave exciting period. However for Case 6 under RW-5, the two adjacent motions superpose, and the pitch response gradually increases and finally oscillates with a long period which just falls into the pitch natural period zone. Therefore, because of the resonant effect, the pitch motion instability occurs. This phenomena is also observed in the experiment executed by Rho et al. [10]. These analytical results can be proven by the 


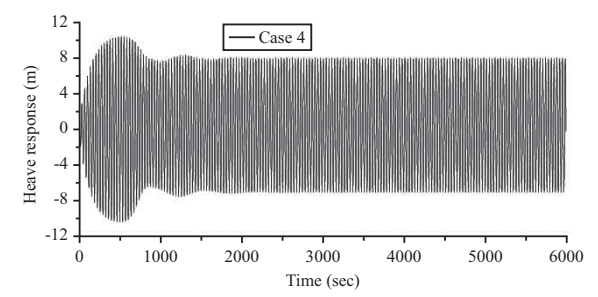

(a) heave response for Case 4

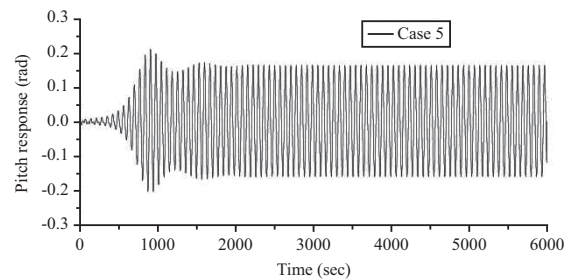

(d) pitch response for Case 5

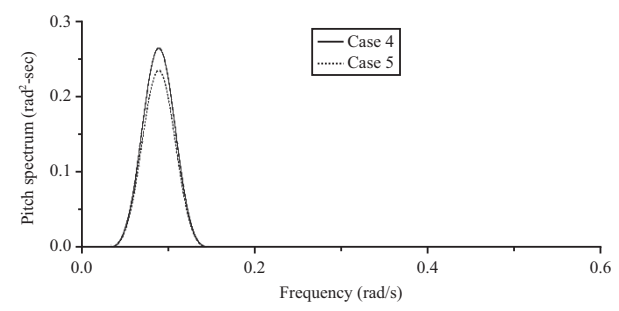

(g) pitch spectra

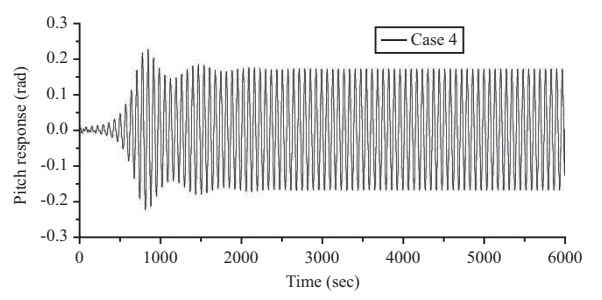

(b) pitch response for Case 4

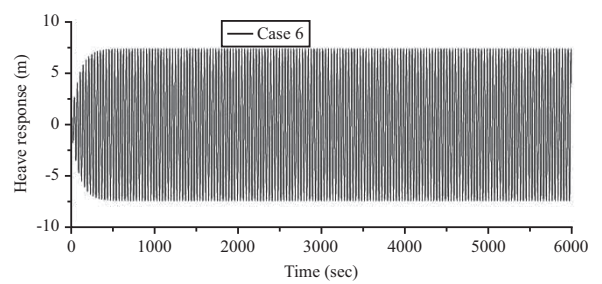

(e) heave response for Case 6

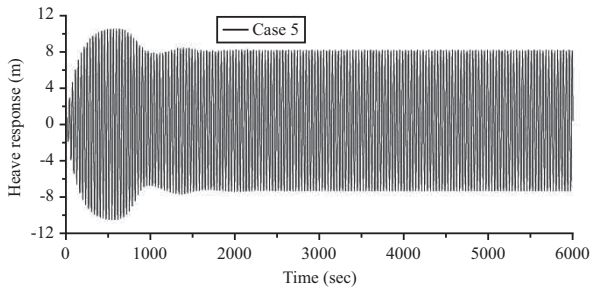

(c) heave response for Case 5

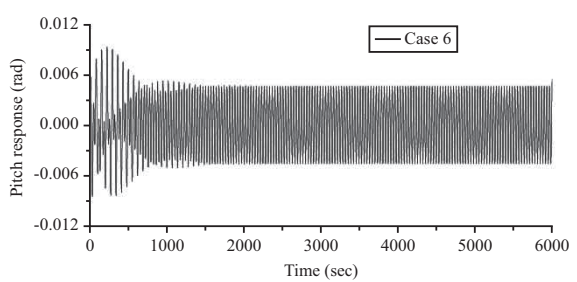

(f) pitch response for Case 6

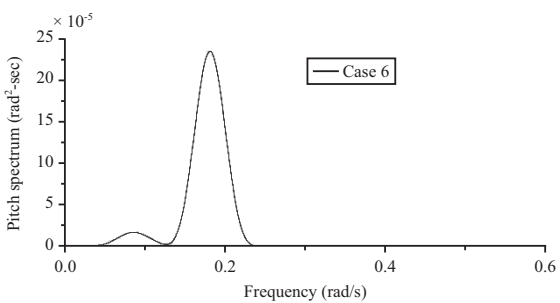

(h) pitch spectrum

Fig. 8. Calculated results under RW-3.

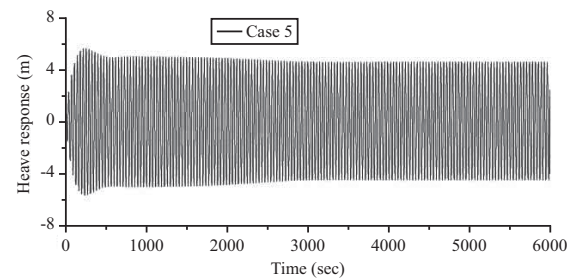

(a) heave response for Case 5, RW-4

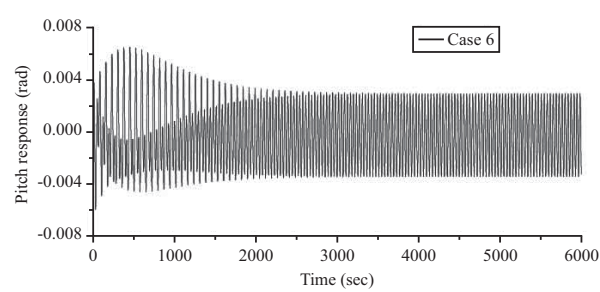

(d) pitch response for Case 6, RW-4

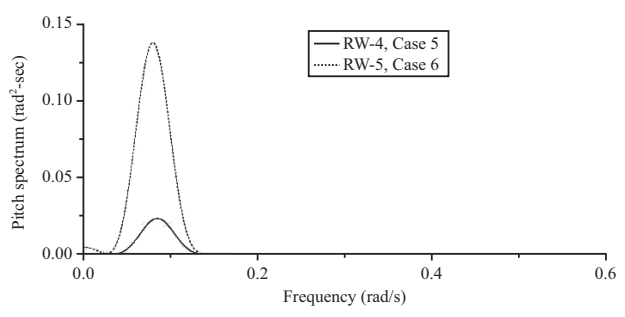

(g) pitch spectra

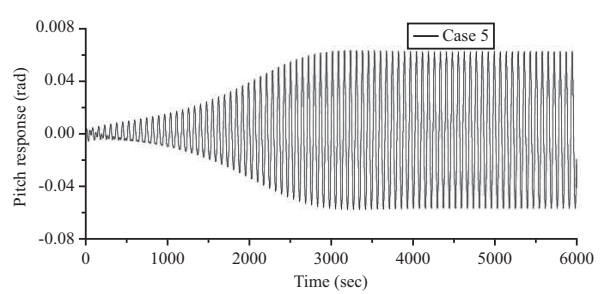

(b) pitch response for Case 5, RW-4

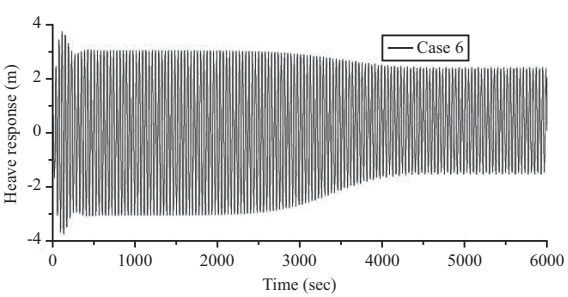

(e) heave response for Case 6, RW-4

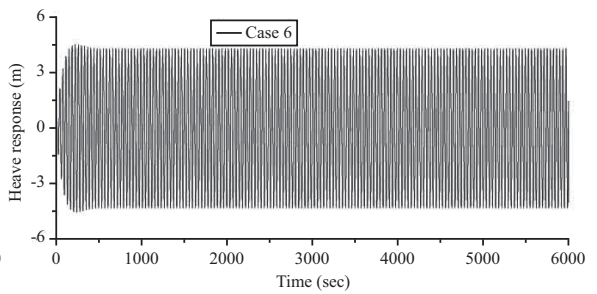

(c) heave response for Case 6, RW-4

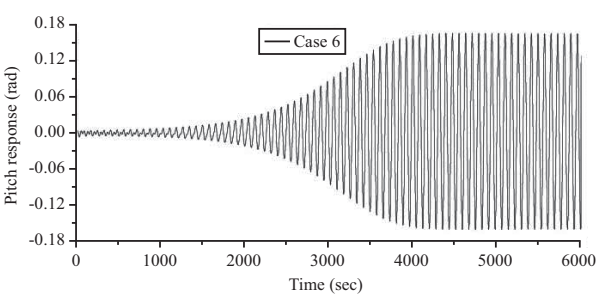

(f) pitch response for Case 6, RW-5

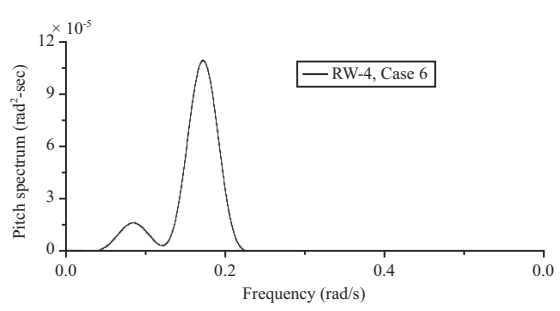

(h) pitch spectra

Fig. 9. Calculated results under RW-4 and RW-5. 


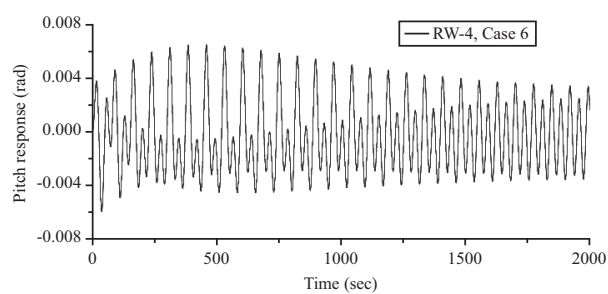

(a)

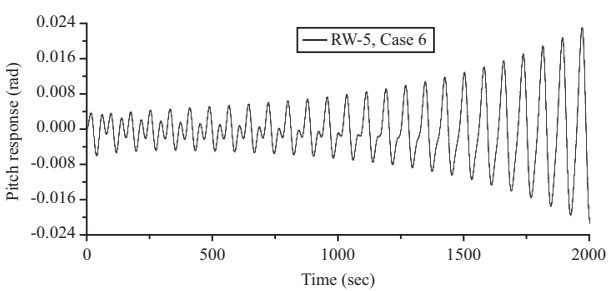

(b)

Fig. 10. (a) Pitch responses for Case 6, RW-4, (b) Pitch responses for Case 6 and RW-5.

Table 6. Random wave conditions.

\begin{tabular}{|c|c|c|c|}
\hline Case & $H_{s}(\mathrm{~m})$ & $T_{p}(\mathrm{sec})$ & $\gamma$ \\
\hline Swell-A & 2.5 & 23.0 & 6.0 \\
\hline Swell-B & 1.7 & 25.0 & 6.0 \\
\hline South China Sea & 15.0 & 15.1 & 3.55 \\
\hline Gulf of Mexico & 12.3 & 14.2 & 2.0 \\
\hline
\end{tabular}

${ }^{*} H_{s}, T_{p}$ and $\gamma$ denote the significant wave height, peak period and peak parameter respectively.

pitch spectra shown in Figs. 9(g) and 9(h), where the wave frequency dominates the spectra of Case 6 under RW-4 while the low frequency dominates the spectra of Case 6 under RW-5.

\section{Random waves action}

In this section, we consider 4 different extreme wave conditions as shown in Table 6 to study the Mathieu instability of DDMS platform under irregular waves. The first 2 cases i.e. Swell-A and Swell-B are a special type of ocean condition which has a long wave period and is also widely observed around the world e.g. West Africa and North Sea. This type of wave may excite large heave motion because the wave period is close to the heave natural period, despite the extraordinary small wave height. In addition, the large heave response is likely to cause the Mathieu instability through the analysis above. Thereby these two typical swell conditions, Swell-A and Swell-B corresponding to the West Africa and North Sea respectively, are selected and investigated on the Mathieu instability. Another two cases in Table 6 are typical extreme wave conditions of 100-y return period for South China sea and Gulf of Mexico. The damping level of Case 4 is employed in this section. In this section, the JONSWAP spectrum is selected to represent random waves. The random wave elevation and exciting forces in time domain are produced by using the Eqs. (8) (10). In order to avoid the repetition of time trace, the wave component number $N$ in Eqs. (8) and (10) is 2000.

The simulated results for swell cases are shown in Figs. 11 14 and the statistical data are summarized in Table 7. The study clearly indicates the Mathieu instability is not generated in swell waves, and the maximum pitch responses are $0.61^{\circ}$ and $0.34^{\circ}$ for Swell-A and Swell-B. As for the heave motion, because the peak period of Swell-B is closer to heave natural
Table 7. Statistics for Swell-A and Swell-B.

\begin{tabular}{|c|c|c|}
\hline Response & Swell-A & Swell-B \\
\hline ABS max heave $(\mathrm{m})$ & 0.92 & 1.19 \\
\hline ABS max Pitch $\left(^{\circ}\right)$ & 0.61 & 0.34 \\
\hline Heave L-F STD $(\mathrm{m})$ & 0.192 & 0.285 \\
\hline Heave W-F STD $(\mathrm{m})$ & 0.121 & 0.110 \\
\hline Pitch L-F STD $\left(^{\circ}\right)$ & 0.034 & 0.019 \\
\hline Pitch W-F STD $\left(^{\circ}\right)$ & 0.104 & 0.068 \\
\hline
\end{tabular}

Table 8. Statistics for South China Sea and Gulf of Mexico.

\begin{tabular}{|c|c|c|}
\hline Response & South China Sea & Gulf of Mexico \\
\hline ABS max heave $(\mathrm{m})$ & 1.689 & 1.354 \\
\hline ABS max pitch $\left({ }^{\circ}\right)$ & 2.417 & 1.655 \\
\hline Heave L-F STD $(\mathrm{m})$ & 0.018 & 0.01 \\
\hline Heave W-F STD $(\mathrm{m})$ & 0.444 & 0.306 \\
\hline Pitch L-F STD $\left(^{\circ}\right)$ & 0.225 & 0.118 \\
\hline Pitch W-F STD $\left(^{\circ}\right)$ & 0.515 & 0.376 \\
\hline
\end{tabular}

period than that of Swell-A, the maximum value of Swell-A is smaller than that of Swell-B although the wave height of Swel-A is larger. In addition, the heave spectra reveals that the resonant responses are adequately excited and entirely dominate the heave motion. As for the pitch motion, the maximum pitch value of Swell-A is nearly 2 times of the one for Swell-B due to the larger wave height. The pitch spectra obviously shows that the wave frequency responses completely dominate the pitch motion, which means pitch resonant responses are not excited, and the instability does not happen.

Figs. 15 17 illustrates the wave spectra, heave and pitch responses as well as the corresponding spectra for South China Sea (SCS) and Gulf of Mexico (GOM) respectively. Table 8 lists the response statistics. We can distinctly observe from the pitch spectra that the pitch motions for both extreme cases are completely controlled by W-F responses and the Mathieu instability is not triggered. The maximal pitch values for both cases are $2.417^{\circ}$ and $1.655^{\circ}$ which are much greater than that of swell cases. The reason is the dramatic increase of the wave heights. The maximal heave responses for both cases are $1.689 \mathrm{~m}$ and $1.354 \mathrm{~m}$ which significantly reflect the favorable 

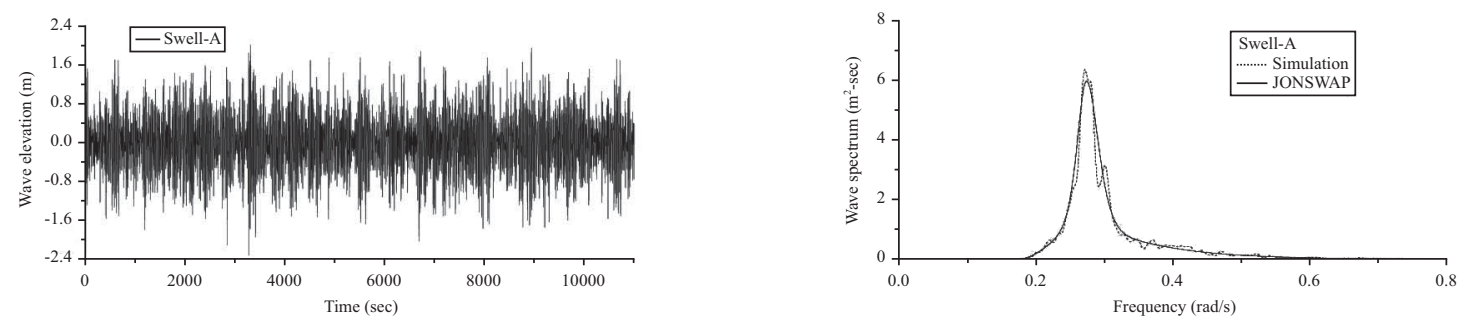

Fig. 11. Wave elevation and spectra of Swell-A.
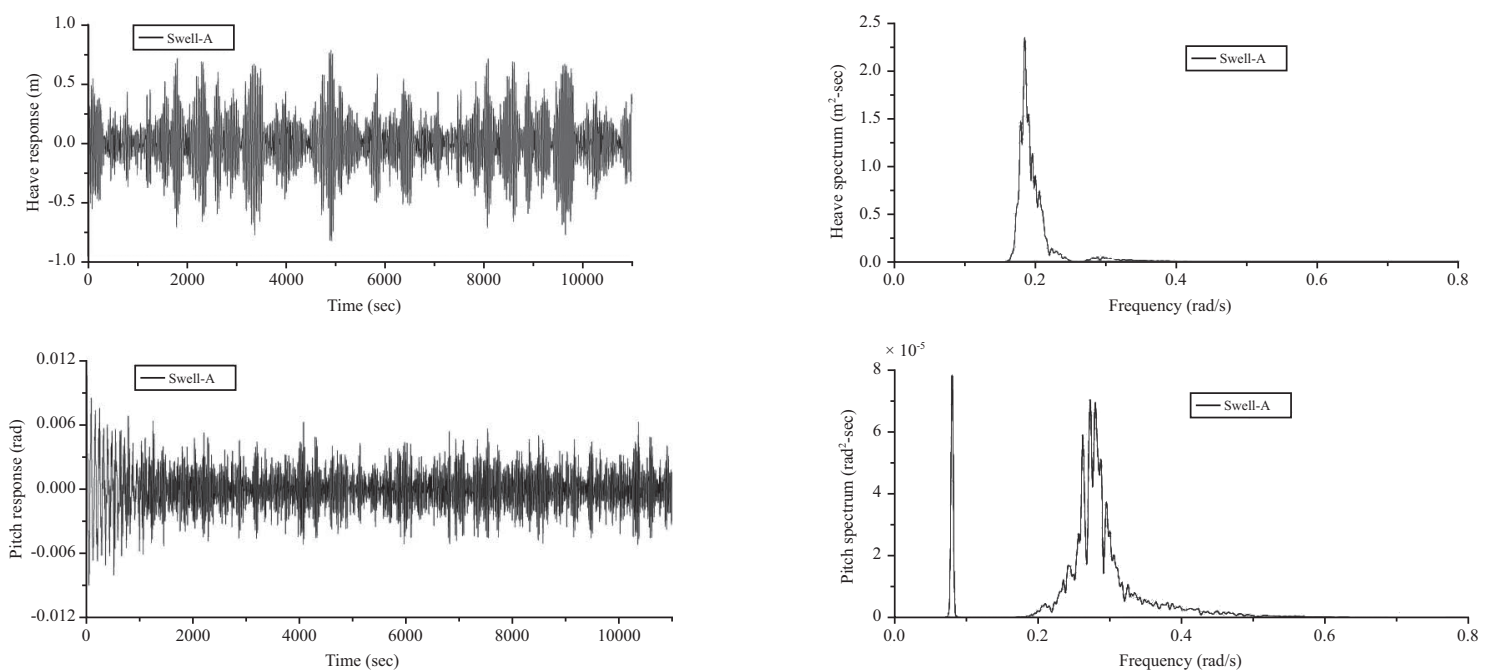

Fig. 12. Heave and pitch responses and spectra of Swell-A.
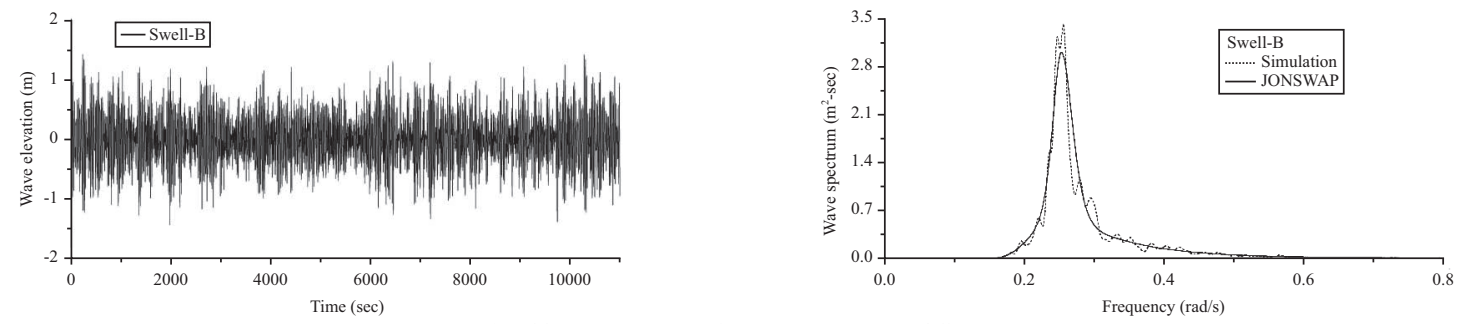

Fig. 13. Wave elevation and spectra of Swell-B.
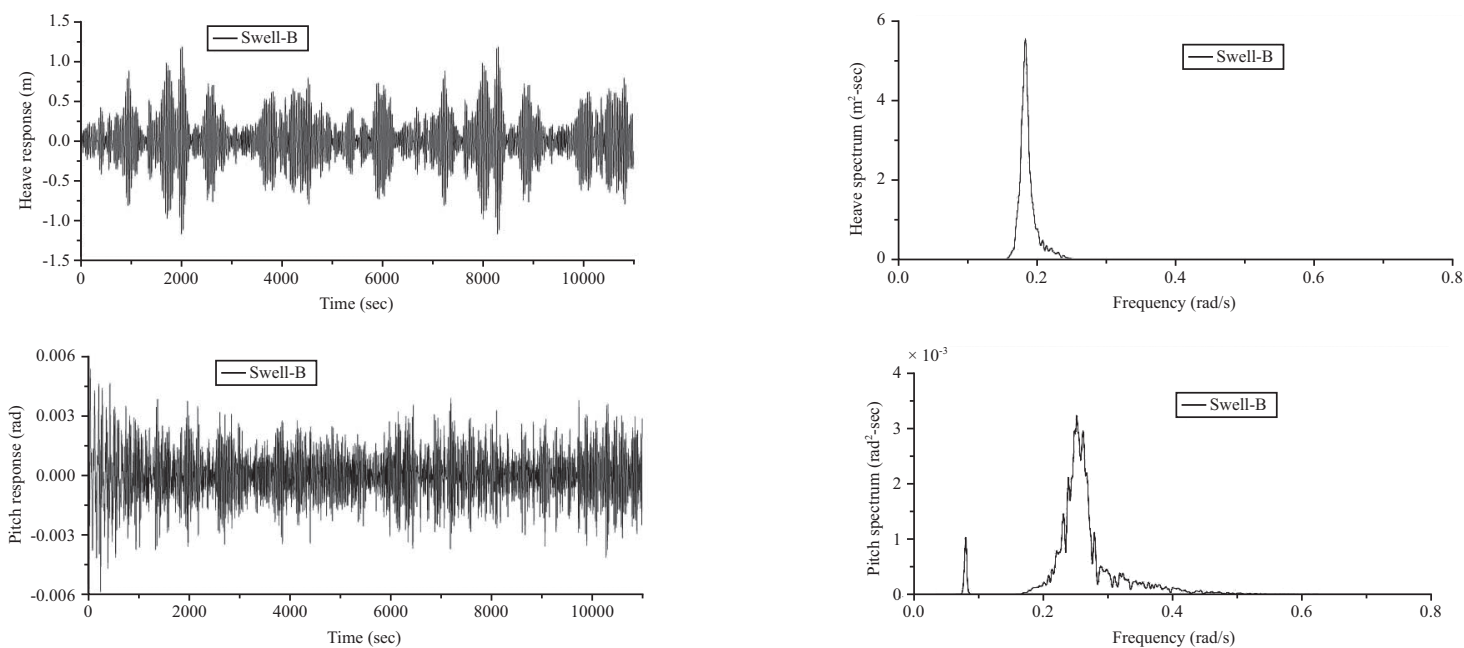

Fig. 14. Heave and pitch responses and spectra of Swell-B. 

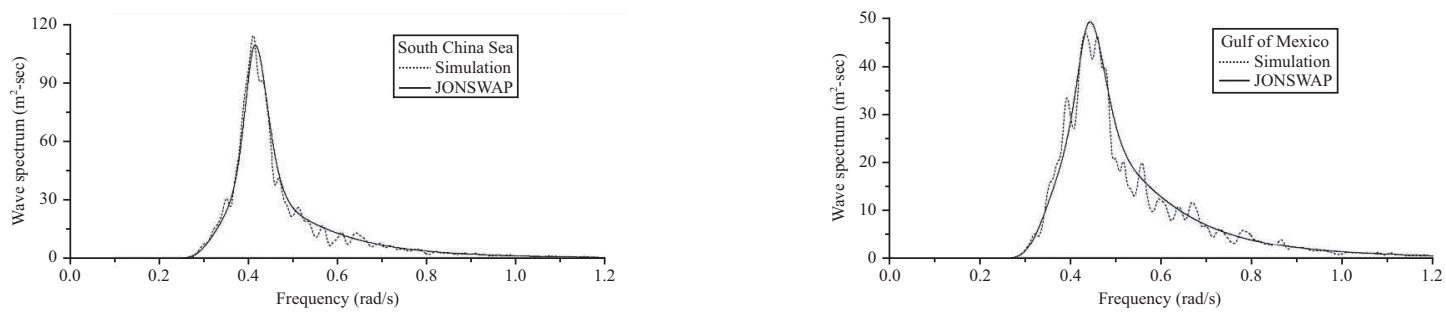

Fig. 15. Wave spectra of South China Sea and Gulf of Mexico.
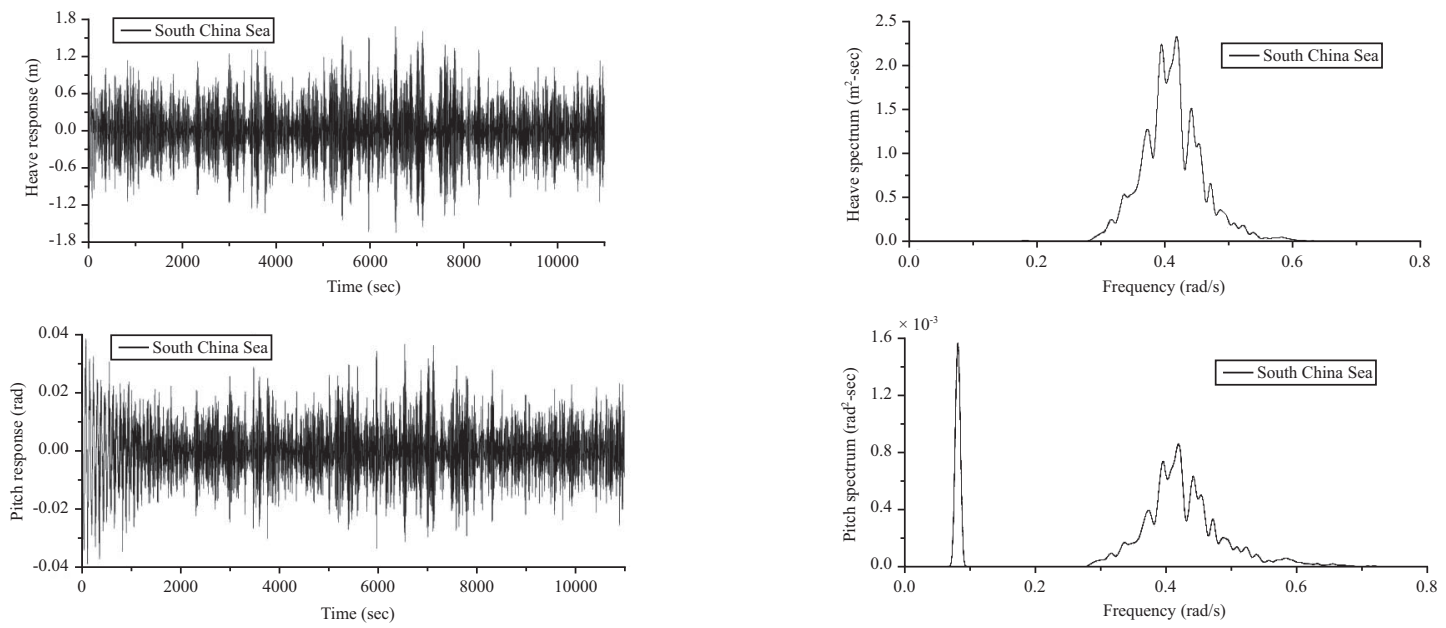

Fig. 16. Heave and pitch responses and spectra of South China Sea.
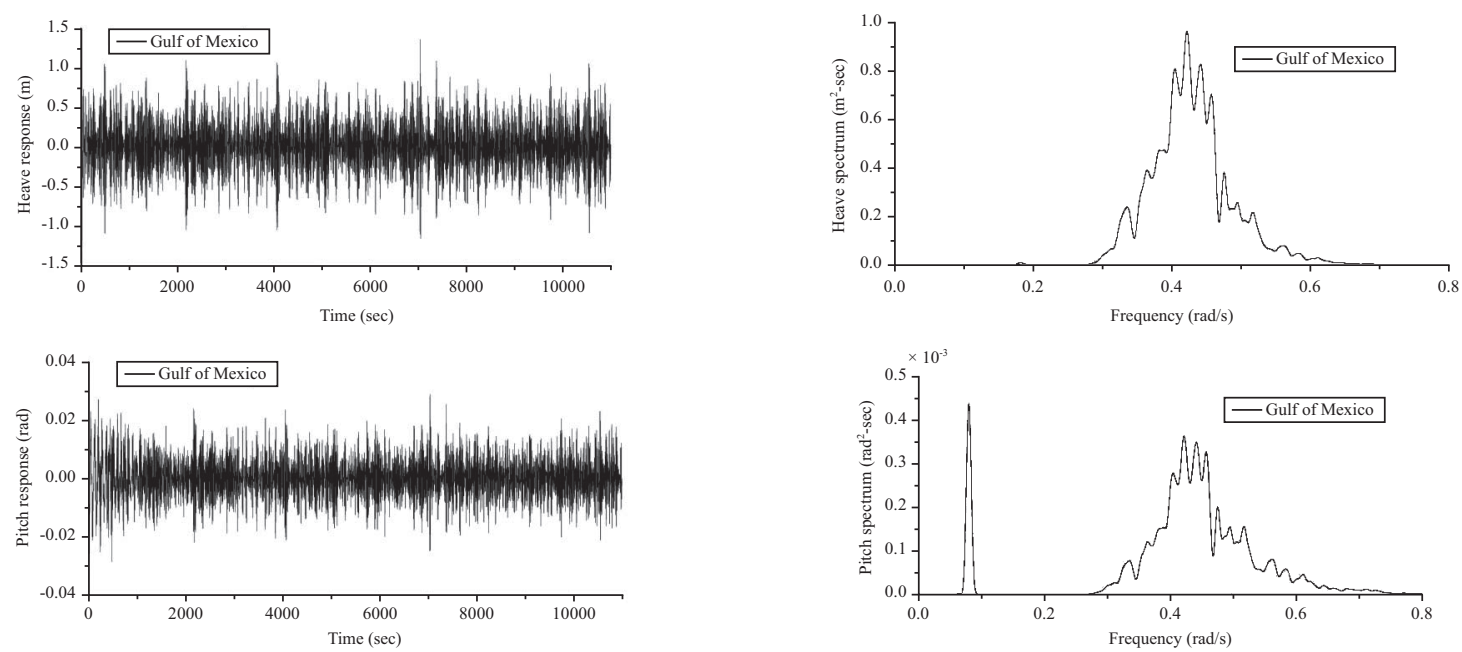

Fig. 17. Heave and pitch responses and spectra of Gulf of Mexico.

seakeeping ability and motion performance of the DDMS platform even under harsh environments. In addition, compared with the prior two swell cases, some differences are obviously observed from the pitch spectra shown in Figs. 16 and 17. The predominant periods of the pitch spectra for SCS and GOM are around the peak period of the wave spectra while the predominant periods for the swell cases are around the heave natural periods. The reason is the peak periods of
SCS and GOM are relative far from the pitch natural periods, and therefore the resonances do not occur.

\section{CONCLUSION}

In this paper, the Mathieu instability of DDMS, an innovative deepwater platform, is investigated. The coupled heave and pitch motion equations are established and solved by 4 th 
order Runge-Kutta method under regular waves and irregular wave conditions. The damping effects on the Mathieu instability are specially studied with different damping cases which are obtained through the coupled hull and mooring model. The main conclusions can be drawn as below:

1. Analyzing the coupled responses with different damping cases, the heave damping significantly dominates the occurrence of Mathieu instability. In other words, suppressing the heave motion can effectively reduce the possibility of pitch instability. In addition, viscous damping of heave plates and hydrodynamic damping of mooring lines play an important role in restraining the instability. The pitch damping accelerates the process of acquiring the steady pitch motion.

2. The numerical simulation clearly indicates the heave and pitch motions increase and decrease turn by turn, and this phenomena is owing to the energy transfer and exchange. Three types of pitch instability are summarized. First, the heave and pitch motion increase and decrease alternately, and steady motions appear after a long time of drastic energy transfers. Second, the pitch motion increases and reaches the peak soon, and subsequently quickly becomes stable after a transitory energy exchange. Third, the pitch motion gradually and gently increases until reaching a peak after a long time, and the energy exchanges slightly.

3 . The calculated results under random waves obviously reveal that the DDMS platform does not suffer from the Mathieu instability. The extreme heave responses under 4 different extreme wave conditions for 4 different areas of the world are very small and do not exceed $2 \mathrm{~m}$ which implies the favorable motion performance of the DDMS platform and the perfect environmental adaptability.

\section{ACKNOWLEDGMENTS}

This research work was financially supported by the National High Technology Research and Development Program of China (863 Program) under Grant No. 2006AA09A103 and National Science-Technology Major Project (No. 2008ZX 05056-03).

\section{REFERENCES}

1. Haslum, H. A. and Faltinsen, O. M., "Alternative shape of spar platforms for use in hostile areas," Proceedings of the 31th Offshore Technology Conference, Houston, USA, pp. 217-228 (1999).

2. Hong, Y. P., Lee, D. Y., Choi, Y. H., Hong, S. K., and Kim, S. E., “An experiment study on the extreme motion responses of a spar platform in the heave resonant waves," Proceedings of the 15th International Offshore and Polar Engineering Conference, Seoul, Korea, Vol. 1, pp. 225-232 (2005).

3. Koo, B. J., Kim, M. H., and Randall, R. E., "Mathieu instability of a spar platform with mooring and risers," Ocean Engineering, Vol. 31, pp. 2175 2208 (2004).

4. Li, B. B. and Ou, J. P., "Numerical simulation on the hydrodynamic and kinetic performance of a new deep draft platform," Proceedings of the 19th International Offshore and Polar Engineering Conference, Osaka, Japan, Vol. 1, pp. 105-112 (2009).

5. Li, B. B., Ou, J. P., and Teng, B., "Stability and hydrodynamic analysis of a deep draft multi-spar platform," The Ocean Engineering, Vol. 28, No. 2, pp. 8-14 (2010). (in Chinese)

6. Li, B. B., Ou, J. P., and Teng, B., "Fully coupled effects of hull, mooring and risers model in time domain based on an innovative deep draft multispar," China Ocean Engineering, Vol. 24, No. 2, pp. 219-233 (2010).

7. Liu, L. Q., Tang, Y. G., and Wang, W. J., "Instability mechanism of coupled heave-pitch motions for spar platform," The Ocean Engineering, Vol. 27, No. 2, pp. 29-35 (2009). (in Chinese)

8. Ran, Z., Kim, M. H., and Zheng, W., "Coupled dynamic analysis of a moored spar in random waves and currents (time-domain versus frequency-domain analysis)," Journal of Offshore Mechanics and Arctic Engineering, Vol. 121, pp. 194-200 (1999).

9. Rho, J. B. and Choi, H. S., "Vertical motion characteristics of truss spar in waves," Proceedings of the 14th International Offshore and Polar Engineering Conference, Toulon, France, pp. 662-665 (2004).

10. Rho, J. B., Choi, H. S., Lee W. S., Shin H. S., and Park, I. K., "Heave and pitch motions of a spar platform with damping plate," Proceedings of the 12th International Offshore and Polar Engineering Conference, Kitakyushu, Japan, pp. 198-201 (2002).

11. Spanos, P. D., Ghosh, R., Finn, L. D., and Halkyard, J., "Coupled analysis of a spar structure: monte carlo and statistical linearization solutions," Journal of Offshore Mechanics and Arctic Engineering, Vol. 127, pp. 1116 (2005). 